(2) Open Access Full Text Article

\title{
Involvement of poly(ADP-ribose) polymerase-I in development of spinal cord injury in Chinese individuals: a Chinese clinical study
}

This article was published in the following Dove Press journal:

Drug Design, Development and Therapy

\author{
Qing-Tao Meng* \\ Guang Yang* \\ Ren-Bo Li \\ Jing-Xin Nie \\ Wei Zhou \\ Hong-De Yu \\ Bo Chen \\ Li Jiang \\ Jing-Bo Shang
}

Department of Spine Surgery, The Third People's Hospital of Dalian, Dalian, People's Republic of China

*These authors contributed equally to this work
Correspondence: Jing-Bo Shang

Department of Spine Surgery, The Third

People's Hospital of Dalian, No 40

Qianshan Road, Gangjingzi District,

Dalian II6033, Liaoning Province,

People's Republic of China

Tel +86 4II 86507500

Email shangjingbol89@hotmail.com
Objective: We aimed to evaluate whether the polymorphism of poly(ADP-ribose) polymerase-1 (PARP-1) is involved as potential risk factor in the development of spinal cord injury (SCI) among Chinese individuals.

Patients and methods: Patients with a confirmed diagnosis of SCI (other than traumatic injury) and healthy individuals with no clinical symptoms of SCI were enrolled at Spinal Cord Injury Care Center, The Third People's Hospital of Dalian, China. Genetic polymorphisms were studied in plasma samples by polymerase chain reaction-restriction fragment length polymorphism assay.

Results: A total of 130 Chinese patients with SCI and 130 healthy Chinese individuals were included. We found that patients with the GG genotype (odds ratio [OR]: 4.09, 95\% confidence interval $[\mathrm{CI}] 2.42-6.90, P<0.001$ ) and carriers of the G allele (OR 3.96, 95\% CI 2.33-6.74, $P<0.0001)$ were at high risk of developing SCI. A del/ins polymorphism of the NF- $\mathrm{KB} 1$ gene (OR 3.32, 95\% CI 1.96-5.61, P<0.001) was also found to be associated with SCI.

Conclusion: Our study suggests that PARP-1 polymorphisms are involved in the development of SCI in Chinese individuals. Thus, PARP-1 polymorphisms can be considered as one of the potential risk factors for developing SCI.

Keywords: spinal cord injury, poly(ADP-ribose) polymerase-1, polymorphism

\section{Introduction}

Spinal cord injury (SCI) is a common cause of disability and has been increasing, with the estimated incidence rate of 15-40 cases per million worldwide. ${ }^{1}$ In China, the incidence of SCI has been doubled in 2011 (14\%) when compared with incidence rate of SCI (7\%) in 2003. ${ }^{2}$ Spinal cord injuries (SCIs) severely affect physical, psychological, and social well-being of patients and significantly enhance financial burden to patients and their family as well as to the health care systems. ${ }^{3}$ Mobility restrictions are one of main problems associated with SCI patients, which increase secondary complications such as obesity, cardiovascular disease, diabetes, depression and pressure ulcers that may negatively influence quality of life. ${ }^{4}$ Guimarães et $\mathrm{al}^{5}$ suggested that polymorphisms were involved in the development of SCI in Brazilian patients.

It is well known that poly(ADP-ribose) polymerase-1 (PARP-1)-mediated signaling can trigger an outburst of pro-inflammatory regulators and the cell death cascade is also known to the scientific community. ${ }^{6}$ PARP-1, also named adenosine diphosphate ribosyltransferase, catalyzes the process of PARylation by attaching the polymers of ADP-ribose to target protein motifs via ester linkage and triggers an array of vital cell functions including chromatin structure, DNA repair, transcriptional 
regulation, apoptosis, necrosis, cell separation, and differentiation. ${ }^{7}$ In humans, 17 members of PARP are expressed, of which PARP-1 is associated with the nucleus and regulates at least $85 \%$ of the cellular PARP activities. ${ }^{8}$ DNA strand nicks/breaks/errors activate PARP-1 and trigger the DNA repair process. ${ }^{9}$ PARP-1 maintains the genomic integrity by PARylation of histones and other key enzymes, the DNA repair mechanism, inter protein interactions, and gene expression to ensure optimum cellular homeostasis. ${ }^{10-13}$ However, through cellular and/or genotoxic stress, prolonged activation of PARP-1 leads to a decrease in $\beta$-nicotinamide adenine dinucleotide (NAD) and adenosine triphosphate (ATP) and causes release of apoptosis-inducing factor (AIF), a mitochondrial proapoptotic protein. Such stress-induced dysregulation in cellular homeostasis mediated by PARP-1 triggers the downstream necrosis cascade of cell death. ${ }^{12}$

PARP plays an important role in the tissue injury associated with neuro-trauma. Infiltration of spinal cord tissue with neutrophils was associated with a marked increase in immunoreactivity for poly(ADP-ribose), which results in the activation of PARP in the spinal cord tissue. This results in the activation of nuclear factor- $\kappa \mathrm{B}(\mathrm{NF}-\kappa \mathrm{B})$ after spinal cord damage. ${ }^{14}$ Recently, it has been demonstrated that SCI induced PARP activation. Continuous or excessive activation of PARP produces extended chains of ADP-ribose on nuclear proteins and results in a substantial depletion of intracellular $\mathrm{NAD}^{+}$and, subsequently, adenosine triphosphate (ATP), leading to cellular dysfunction and, ultimately, cell death. ${ }^{15}$ Involvement of PARP in the neurological consequence of traumatic brain injury as well as in SCI, considered PARP as a promising therapeutic target in the clinical treatment of brain trauma or SCI. ${ }^{16}$ The main objective of our study was to ascertain whether such polymorphisms also play a role in Chinese patients with SCI given the different involvement of gene polymorphisms based on ethnicity. This pilot study was designed to investigate whether there is any ethnic difference in gene involvement between Chinese and Brazilian patients with SCI. Our study may serve as a basis for conducting large multicenter and multicountry clinical studies to assess the association of PARP-1 with SCI.

\section{Patients and methods}

Patients of both genders aged between 18 and 65 years with a confirmed diagnosis of SCI and healthy individuals with no SCI (control group) were enrolled at Spinal Cord Injury Care Center, The Third People's Hospital of Dalian, Affiliated to Dalian Medical University, Dalian, China. Subjects with complete neurological damage after SCI met all the following inclusion criteria: 1) had neurological damage caused by SCI at least for 1 year; 2) subjects with no vertebral canal stenosis at the time of the SCI; 3) subjects who had burst vertebral fracture, in the absence of facet dislocation, at the level of the spinal cord in the vertebral canal, and not at the level of the spinal cord cone or the nervous roots; 4 ) subjects with age $<65$ years at the time of the injury; and 5) who did not experience neurological alterations as a result of surgical intervention.

The study was approved by the Institutional Review Board of Dalian Medical University, and written consent was obtained from each study participant. All participants were informed about the study procedures and the potential benefits to society. All participants underwent laboratory tests to confirm their eligibility as healthy individuals and patients with SCI.

Plasma samples were collected from the study population and DNA from leukocytes was extracted by the high salt DNA extraction method. All isolated DNA samples were kept at $-80^{\circ} \mathrm{C}$ for further assessment. Using efficient molecular biology techniques, polymorphisms of the PARP-1, NF- $\kappa \mathrm{B} 1$, and NF- $\kappa \mathrm{BIA}$ genes were studied in DNA samples by polymerase chain reaction-restriction fragment length polymorphism analysis. For the PARP-1 C410T and G1672A promoter regions, 297 and 187 base pair polymerase chain reaction (PCR) fragments were amplified in a $25 \mu \mathrm{L}$ reaction volume at $\mathrm{pH} 8.3$ consisting of $50 \mathrm{mM}$ potassium chloride (KCl), 100 ng genomic DNA, 200 pM deoxynucleotide (dNTP), 200 pM of $10 \mathrm{mM}$ Tris-hydrogen chloride (HCl), 1 U Taq polymerase (Sigma-Aldrich, St Louis, MO, USA) and $2 \mathrm{mM} \mathrm{MgCl}_{2}$ (Thermo Fisher Scientific, Waltham, MA, USA). PCR was performed using an optimized sequence of cycles: a denaturation phase at $95^{\circ} \mathrm{C}$ ( $2 \mathrm{~min})$ followed by 30 cycles at $95^{\circ} \mathrm{C}(30 \mathrm{~s}), 60^{\circ} \mathrm{C}(30 \mathrm{~s})$, $72^{\circ} \mathrm{C}(1 \mathrm{~min})$, and a final incubation phase at $72^{\circ} \mathrm{C}(5 \mathrm{~min})$. The PCR products were treated with $5 \mathrm{U}$ of HpyF3I (DdeI) (Thermo Fisher Scientific) and Bsh1236I (Thermo Fisher Scientific) at $37^{\circ} \mathrm{C}$ overnight for digestion. The resulting fragments were run on ethidium bromide-stained 3\% agarose gel for $45 \mathrm{~min}$ at $90 \mathrm{~V}$ and quantified through direct detection under ultraviolet (UV) light. Likewise, the NF- $\mathrm{KB} 1$ and NF-кBIA genes were amplified by 285 and 424 base pair PCR fragments using the same reagents. The PCR running sequence included a denaturing step at $95^{\circ} \mathrm{C}(1 \mathrm{~min})$ followed by 35 cycles at $95^{\circ} \mathrm{C}(30 \mathrm{~s}), 61^{\circ} \mathrm{C}(30 \mathrm{~s}), 72^{\circ} \mathrm{C}(1 \mathrm{~min})$, and a final incubation at $72^{\circ} \mathrm{C}(5 \mathrm{~min})$. The PCR products were treated with 5 U PfIMI (Van91I) and HaeIII (BsuRI) (Thermo Fisher Scientific) at $37^{\circ} \mathrm{C}$ overnight for digestion, and the digested products were run on ethidium bromide-stained 
$3 \%$ agarose gel for $45 \mathrm{~min}$ at $90 \mathrm{~V}$ and quantified directly under UV light.

\section{Statistical analysis}

The study was designed as a preliminary pilot study to assess the association of PARP-1 with SCI in a Chinese population. Hence, no formal sample size calculation was performed. We planned to enroll at least 100 individuals in each group (SCI patients and healthy controls). We designed our study to serve as a basis for large genetic clinical studies to assess PARP-1 polymorphism in patients with SCI. The data were analyzed using the GraphPad Prism (ver 6.0). Quantitative variables were presented as mean ( \pm standard deviation) and analyzed by parametric and nonparametric statistical tests depending on the number of groups for comparison and the distribution of data; two-sided statistical tests were used. Normality testing (Kolmogorov-Smirnov test or ShapiroWilk test) was used to check the distribution of quantitative data. Categorical variables were presented as absolute numbers and/or percentages of subjects in each category. Odds ratios (ORs) were calculated using logistic regression analysis with age and gender as covariates.

\section{Results}

A total of 130 Chinese patients with SCI and 130 healthy individuals were enrolled and completed the study. The data of all individuals of both groups were subjected to statistical analysis. The mean age of the patients with SCI and healthy groups was $47.9( \pm 6.3)$ and $49.7( \pm 5.6)$ years, respectively. Gender distribution was similar in the patient and control groups. Body mass index was comparable among individuals of both groups (Table 1). In SCI group, the majority of patients had moderate severity of neurological damage. In SCI group, the number of patients with different type of SCI mechanism is presented in Table 1.

For the G1672A genotype, we found that individuals with a GG genotype in the PARP-1 gene were at very high risk of developing SCI (OR 4.09, 95\% confidence interval $[\mathrm{CI}] 2.42-6.90, P<0.001)$. We observed that individuals with a $\mathrm{G}$ allele in PARP-1 were also at very high risk of developing SCI (OR 3.96, 95\% CI 2.33-6.74, $P<0.0001$ ). There was no involvement of other genotypes such as GA and AA among patients with SCI. None of the other genotypes of NF-אB1, NF-KBIA, and PARP-1 were found to be involved (Table 2). No evidence of PARP-1 polymorphisms was observed in healthy subjects.

For the C410T genotype, we observed that individuals with a $\mathrm{C}$ allele in the PARP-1 gene were at high risk of
Table I Demographic and clinical characteristics of healthy individuals and spinal cord injury patients

\begin{tabular}{|c|c|c|}
\hline Variables & $\begin{array}{l}\text { Individuals with } \\
\text { spinal cord injury, } \\
\mathrm{N}=130\end{array}$ & $\begin{array}{l}\text { Healthy } \\
\text { individuals, } \\
\mathrm{N}=130\end{array}$ \\
\hline Age & $47.9(6.3)$ & $49.7(5.6)$ \\
\hline Gender (men/women) & $80 / 50$ & $78 / 52$ \\
\hline BMI & $27.13(3.45)$ & $26.82(3.43)$ \\
\hline \multicolumn{3}{|l|}{$\begin{array}{l}\text { Spinal cord injury mechanism } \\
\text { type, } \mathrm{n}(\%)\end{array}$} \\
\hline Axial deformation & $23(18)$ & $0(0)$ \\
\hline Compression & $21(16)$ & $0(0)$ \\
\hline Spinal elongation with distraction & $21(16)$ & $0(0)$ \\
\hline Torsion or axial spinal rotation & $14(11)$ & $0(0)$ \\
\hline Segmental translation & $27(2 \mathrm{I})$ & $0(0)$ \\
\hline Combined mechanisms & $24(18)$ & $0(0)$ \\
\hline \multicolumn{3}{|l|}{$\begin{array}{l}\text { Severity of neurological damage, } \\
\mathrm{n}(\%)\end{array}$} \\
\hline Moderate & $103(79)$ & $0(0)$ \\
\hline Severe & $27(2 \mathrm{I})$ & $0(0)$ \\
\hline
\end{tabular}

Notes: Values are expressed as mean (SD) for age and $\mathrm{BMI}$, and absolute values are presented for gender. $\mathrm{N}$, total number of individuals.

Abbreviations: BMI, body mass index; SD, standard deviation.

developing SCI (OR 3.77, 95\% CI 1.99-7.12, $P<0.0001$ ). Among patients with SCI, a DNA sequence variation, namely del/ins of the NF- $\mathrm{KB} 1$ gene, was observed (OR 3.32, 95\% CI 1.96-5.61, $P<0.001)$. This suggests a role of del/ins of NF-KB1 in the development of SCI. No statistically significant association of other NF- $\mathrm{\kappa B} 1$ genotypes with SCI was observed (Table 2). In our study, polymorphism of PARP-1 was not associated with any worse recovery outcome among the patients with SCI.

\section{Discussion}

This was the first study to determine the association of PARP-1 polymorphisms with the development of SCI in Chinese patients. We found that individuals with the GG genotype were at very high risk of developing SCI. Guimarães et $\mathrm{a}^{5}$ have identified $>95,000$ SNPs in 588 genes associated with SCI in Brazilian patients. Among the identified genes, the following genes were selected for frequency analysis in Guimarães et al's study: APOE, ALOX12, BDNF, and NINJ1. Guimarães et $\mathrm{al}^{5}$ suggested that the polymorphism of ALOX12 is highly prevalent in both SCI (42.8\%) and non-SCI samples (39.5\%) being an excellent candidate for future study. In addition to Guimarães et al's study, ${ }^{5}$ our study results suggested the involvement of two SNPs of PARP-1 (C410T and G1672A) with SCI in China, indicating that polymorphism of PARP-1 could increase the susceptibility of SCI. In this Chinese study, we also observed that individuals carrying a $\mathrm{C}$ allele were at high risk of developing 
Table 2 Genotypes involved in gene polymorphism in patients with spinal cord injury

\begin{tabular}{|c|c|c|c|}
\hline Genotype & $\begin{array}{l}\text { Individuals } \\
\text { with spinal } \\
\text { cord injury, } \\
N=130\end{array}$ & $\begin{array}{l}\text { Healthy } \\
\text { individuals, } \\
\mathbf{N}=130\end{array}$ & OR (95\% CI), P-value \\
\hline \multicolumn{4}{|l|}{ GI672A } \\
\hline \multicolumn{4}{|l|}{ genotype } \\
\hline GG & 88 & 42 & $\mathrm{I} .47(\mathrm{I} .42-3.20),<0.00 \mathrm{I}$ \\
\hline GA & 43 & 41 & I.0I (0.63-I.40), 0.87 \\
\hline AA & 22 & 21 & 1.03 (0.54-2.03), 0.9 \\
\hline \multicolumn{4}{|c|}{ Allele frequency } \\
\hline \multicolumn{4}{|c|}{ in GI672A } \\
\hline \multicolumn{4}{|l|}{ genotype } \\
\hline G allele & 72 & 31 & $1.64(1.38-3.14),<0.001$ \\
\hline A allele & 34 & 32 & I.06 (0.65-I.49), 0.87 \\
\hline \multicolumn{4}{|l|}{ C4IOT } \\
\hline \multicolumn{4}{|l|}{ genotype } \\
\hline $\mathrm{CC}$ & 86 & 78 & I.II (0.78-I.85), 0.08 \\
\hline $\mathrm{CT}$ & 34 & 32 & $1.03(0.92-1.31), 0.83$ \\
\hline TT & 18 & 14 & I.0I (0.87-I.19), 0.78 \\
\hline \multicolumn{4}{|c|}{ Allele frequency } \\
\hline \multicolumn{4}{|l|}{ in C4IOT } \\
\hline $\mathrm{C}$ allele & 114 & 85 & $1.77(1.69-3.12),<0.0001$ \\
\hline T allele & 33 & 31 & I.0I (0.7I-I.65), 0.82 \\
\hline \multicolumn{4}{|c|}{ NF-KBI gene } \\
\hline ins/ins & 84 & 82 & $\mathrm{I} .04$ (0.74-I.57), $0.8 \mathrm{I}$ \\
\hline del/ins & 69 & 33 & $1.32(1.26-2.91),<0.001$ \\
\hline $\mathrm{del} / \mathrm{del}$ & 15 & 11 & I.3। (0.62-2.12), 0.73 \\
\hline \multicolumn{4}{|c|}{ Allele frequency } \\
\hline \multicolumn{4}{|l|}{ in NF-кBI } \\
\hline ins & 81 & 78 & I.II (0.74-I.63), 0.78 \\
\hline \multicolumn{4}{|c|}{ NF-KBIA gene } \\
\hline AA & 91 & 84 & 0.82 (0.74-I.II), 0.73 \\
\hline AG & 25 & 21 & 1.02 (0.79-1.19), 0.82 \\
\hline GG & 13 & 21 & $1.14(0.88-1.91), 0.75$ \\
\hline \multicolumn{4}{|c|}{ Allele frequency } \\
\hline \multicolumn{4}{|c|}{ in NF- $\kappa B I A$} \\
\hline A allele & 64 & 67 & I. $13(0.8 \mathrm{I}-1.82), 0.72$ \\
\hline G allele & 52 & 48 & $1.09(0.76-1.63), 0.72$ \\
\hline
\end{tabular}

Notes: Values are expressed as absolute number. $\mathrm{N}$, total number in each group. OR values were calculated based on using logistic regression analysis with age and gender as covariates.

Abbreviations: $\mathrm{Cl}$, confidence interval; OR, odds ratio.

SCI. Additionally, we observed the involvement of a del/ins

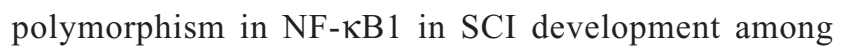
Chinese individuals.

In our study, individuals with a GG genotype in DNA sequencing and carriers of a $\mathrm{G}$ allele were more susceptible to and at very high risk of developing SCI. This indicates that a GA genotype might have a defensive influence on the disease. The possible reason for involvement of the GG genotype as a risk factor for SCI could be explained by molecular heterosis, which is observed in $\sim 50 \%$ of cases of gene associations. ${ }^{17} \mathrm{We}$ also observed the involvement of a NF-KB1 polymorphism in the increased risk of SCI. Our study results showed involvement of PARP in SCI, indicating PARP as a promising therapeutic target in clinical treatment of SCI. In addition, previous study demonstrated that PARP inhibitors inhibit apoptotic cell death in spinal cord tissue by preventing the activation of the apoptosis pathway..$^{14}$ Also, preclinical evidence demonstrated that the PARP inhibitors clearly improve motor function associated with SCI. In addition, reports indicate that PARP inhibitors have strong anti-inflammatory properties resulting in reduced 1) polymorphonuclear leukocyte infiltration, 2) activation of NF- $\mathrm{kB}$, and 3) degree of tissue injury. ${ }^{14-17}$ Differential expression of the desired gene product in the target tissue is central to the concept of gene therapy. ${ }^{18}$ The development of potent PARP inhibitors has become of increasing clinical interest in various disease conditions. In this study, we suggest the PARP inhibitor-based gene therapy as a new treatment paradigm for SCI. Our study results provide proof-of-principle for a novel therapeutic strategy for the treatment of SCI.

This was the first study to suggest the association of two single-nucleotide polymorphisms (SNPs) of PARP-1 (C410T and G1672A) with SCI in Chinese patients. The involvement of these SNPs in SCI subtypes has not yet been established. PARP-1 catalyzes poly(ADP-ribosyl) ation to various proteins involved in many cellular processes, including DNA damage detection and repair and cell proliferation and death. ${ }^{19}$ Several reports showed the involvement of polymorphisms of PARP-1 in susceptibility of developing various diseases such as cancer, ${ }^{19}$ cataract, ${ }^{20}$ and Graves' disease. ${ }^{21}$ Thus, our finding encourages the researchers to focus on two SNPs of PARP-1 (C410T and G1672A) in other disease conditions associated with SCI. The study was designed as pilot study and conducted at single study center in China (limitation of study). Therefore, the present findings cannot be generalized to the overall Chinese population. Based on the study results, we encourage conducting large multicentric randomized clinical study in future to generalize our findings.

\section{Conclusion}

Our results suggest that polymorphisms of the PARP-1 gene could be considered as one of potential risk factors for the development of SCI in Chinese individuals. We also observed the involvement of a NF- $\mathrm{KB} 1$ polymorphism in the increased risk of SCI. Our study results may serve as a basis for conducting large multicenter, multicountry, genetic clinical studies to assess the involvement of PARP-1 and $\mathrm{NF}-\kappa \mathrm{B} 1$ in SCI. 


\section{Acknowledgments}

The authors thank all patients for their participation in the study. We would also like to thank Dr Rakesh Ojha (senior consultant medical writer) for writing and editorial support in the preparation of this article.

\section{Disclosure}

The authors report no conflicts of interest in this work.

\section{References}

1. Behrman AL, Trimble SA. Outcomes of spinal cord injuries in young children. Dev Med Child Neurol. 2012;54:1072-1078.

2. Rui Y, Lan G, Peng W, et al. Epidemiology of spinal cord injuries and risk factors for complete injuries in Guangdong, China: a retrospective study. PLoS One. 2014;9(1):1-10.

3. Burr JF, Shephard RJ, Zehr EP. Physical activity after stroke and spinal cord injury: evidence-based recommendations on clearance for physical activity and exercise. Can Fam Physician. 2012;58(11):1236-1239.

4. Levine S. The meanings of health, illness, and quality of life. In: Guggenmoos-Holzmann I, Bloomfield K, Brenner H, Flick U, editors. Quality of Life and Health. Concepts, Methods and Applications. Berlin: Blackwell; 1995:7-16.

5. Guimarães PE, Fridman C, Gregório SP, et al. DNA polymorphisms as tools for spinal cord injury research. Spinal Cord. 2009;47(2): 171-175.

6. Smulson ME, Simbulan-Rosenthal CM, Boulares AH, et al. Roles of poly(ADP-ribosyl)ation and PARP in apoptosis, DNA repair, genomic stability and functions of p53 and E2F-1. Adv Enzyme Regul. 2000;40(1):183-215.

7. Corcoran NM, Clarkson MJ, Stuchbery R, Hovens CM. Molecular pathways: targeting DNA repair pathway defects enriched in metastasis. Clin Cancer Res. 2016;22(13):3132-3137.

8. Hassa PO, Hottiger MO. The diverse biological roles of mammalian PARPS, a small but powerful family of poly-ADP-ribose polymerases. Front Biosci. 2008;13(13):3046-3082.

9. Phulwani NK, Kielian T. Poly (ADP-ribose) polymerases (PARPs) 1-3 regulate astrocyte activation. J Neurochem. 2008;106(2):578-590.
10. Ba X, Garg NJ. Signaling mechanism of poly(ADP-ribose) polymerase-1 (PARP-1) in inflammatory diseases. Am J Pathol. 2011;178(3): 946-955.

11. Chiarugi A, Moskowitz MA. Poly(ADP-ribose) polymerase-1 activity promotes NF-kappaB-driven transcription and microglial activation: implication for neurodegenerative disorders. J Neurochem. 2003; 85(2):306-317.

12. Yu SW, Wang H, Poitras MF, et al. Mediation of poly(ADP-ri-bose) polymerase-1-dependent cell death by apoptosis-inducing factor. Science. 2002;297(5579):259-263.

13. Albulescu R, Codrici E, Popescu ID, et al. Cytokine patterns in brain tumour progression. Mediators Inflamm. 2013;2013:979748.

14. Genovese T, Mazzon E, Muià C, et al. Inhibitors of poly(ADP-ribose) polymerase modulate signal transduction pathways and secondary damage in experimental spinal cord trauma. J Pharmacol Exp Ther. 2005;312(2):449-457.

15. Chiarugi A. Poly(ADP-ribose) polymerase: killer or conspirator? The 'suicide hypothesis' revisited. Trends Pharmacol Sci. 2002;23: 22-129.

16. Scott GS, Jakeman LB, Stokes BT, Szabó C. Peroxynitrite production and activation of poly (adenosine diphosphate-ribose)synthetase in spinal cord injury. Ann Neurol. 1999;45:120-124.

17. Comings DE, MacMurray JP. Molecular heterosis: a review. Mol Genet Metab. 2000;71(1-2):19-31.

18. Trofimova I, Dimtchev A, Jung M, et al. Gene therapy for prostate cancer by targeting poly(ADP-ribose) polymerase. Cancer Res. 2002; 62(23):6879-6883.

19. Yu H, Ma H, Yin M, Wei Q. Association between PARP-1 V762A polymorphism and cancer susceptibility: a meta-analysis. Genet Epidemiol. 2012;36(1):56-65.

20. Cui NH, Qiao C, Chang XK, Wei L. Associations of PARP-1 variant rs1136410 with PARP activities, oxidative DNA damage, and the risk of age-related cataract in a Chinese Han population: a two-stage casecontrol analysis. Gene. 2017;600:70-76.

21. Niyazoglu M, Baykara O, Koc A, et al. Association of PARP-1, NF- $\kappa$ B NF- $\kappa$ BIA and IL-6, IL-1 $\beta$ and TNF- $\alpha$ with graves disease and graves ophthalmopathy. Gene. 2014;547(2):226-232.

\section{Publish your work in this journal}

Drug Design, Development and Therapy is an international, peerreviewed open-access journal that spans the spectrum of drug design and development through to clinical applications. Clinical outcomes, patient safety, and programs for the development and effective, safe, and sustained use of medicines are the features of the journal, which has also been accepted for indexing on PubMed Central. The manuscript management system is completely online and includes a very quick and fair peer-review system, which is all easy to use. Visit http://www.dovepress.com/testimonials.php to read real quotes from published authors. 